OPEN ACCESS

Edited by:

Ana Pineda,

Netherlands Institute of Ecology

(NIOO-KNAW), Netherlands

Reviewed by:

Martin Schädler,

Helmholtz-Zentrum für

Umweltforschung (UFZ), Germany

Sharon E. Zytynska,

Technische Universität München,

Germany

${ }^{*}$ Correspondence:

Scott N. Johnson

scott.johnson@westernsydney.edu.au;

scott.johnson@uws.edu.au

tPresent address:

Adam Frew,

School of Agricultural and Wine

Sciences, Charles Sturt University,

Bathurst, NSW, Australia

Specialty section:

This article was submitted to

Functional Plant Ecology,

a section of the journal

Frontiers in Plant Science

Received: 10 November 2017 Accepted: 02 February 2018

Published: 20 February 2018

Citation:

Johnson SN, Ryalls JMW,

Gherlenda AN, Frew A and Hartley SE (2018) Benefits from

Below: Silicon Supplementation Maintains Legume Productivity under Predicted Climate Change Scenarios.

Front. Plant Sci. 9:202.

doi: 10.3389/fpls.2018.00202

\section{Benefits from Below: Silicon Supplementation Maintains Legume Productivity under Predicted Climate Change Scenarios}

\author{
Scott N. Johnson ${ }^{1 *}$, James M. W. Ryalls ${ }^{1}$, Andrew N. Gherlenda ${ }^{1}$, Adam Frew ${ }^{1 \dagger}$ and \\ Susan E. Hartley ${ }^{2}$ \\ ${ }^{1}$ Hawkesbury Institute for the Environment, Western Sydney University, Penrith, NSW, Australia, ${ }^{2}$ York Environmental \\ Sustainability Institute, Department of Biology, University of York, York, United Kingdom
}

Many studies demonstrate that elevated atmospheric carbon dioxide concentrations $\left(\mathrm{eCO}_{2}\right)$ can promote root nodulation and biological nitrogen fixation (BNF) in legumes such as lucerne (Medicago sativa). But when elevated temperature (eT) conditions are applied in tandem with $\mathrm{eCO}_{2}$, a more realistic scenario for future climate change, the positive effects of $\mathrm{eCO}_{2}$ on nodulation and $\mathrm{BNF}$ in $M$. sativa are often much reduced. Silicon (Si) supplementation of $M$. sativa has also been reported to promote root nodulation and BNF, so could potentially restore the positive effects of $\mathrm{eCO}_{2}$ under eT. Increased nitrogen availability, however, could also increase host suitability for aphid pests, potentially negating any benefit. We applied $\mathrm{eCO}_{2}(+240 \mathrm{ppm})$ and eT $\left(+4^{\circ} \mathrm{C}\right)$, separately and in combination, to $M$. sativa growing in Si supplemented $(\mathrm{Si}+)$ and un-supplemented soil $(\mathrm{Si}-)$ to determine whether $\mathrm{Si}$ moderated the effects of $\mathrm{eCO}_{2}$ and eT. Plants were either inoculated with the aphid Acyrthosiphon pisum or insect-free. In $\mathrm{Si}$ - soils, $\mathrm{eCO}_{2}$ stimulated plant growth by $67 \%$ and nodulation by $42 \%$, respectively, whereas eT reduced these parameters by 26 and $48 \%$, respectively. Aphids broadly mirrored these effects on $\mathrm{Si}$ - plants, increasing colonization rates under $\mathrm{eCO}_{2}$ and performing much worse (reduced abundance and colonization) under eT when compared to ambient conditions, confirming our hypothesized link between root nodulation, plant growth, and pest performance. Examined across all $\mathrm{CO}_{2}$ and temperature regimes, Si supplementation promoted plant growth $(+93 \%)$, and root nodulation (+50\%). A. pisum abundance declined sharply under $\mathrm{e} T$ conditions and was largely unaffected by Si supplementation. In conclusion, supplementing $M$. sativa with $\mathrm{Si}$ had consistent positive effects on plant growth and nodulation under different $\mathrm{CO}_{2}$ and temperature scenarios. These findings offer potential for using Si supplementation to maintain legume productivity under predicted climate change scenarios without making legumes more susceptible to insect pests.

Keywords: alfalfa, aphids, atmospheric change, climate change, global warming, silica, silicon 


\section{INTRODUCTION}

Projected increases in atmospheric carbon dioxide $\left(\mathrm{CO}_{2}\right)$ have been shown experimentally to stimulate biological nitrogen fixation (BNF) in legumes (Soussana and Hartwig, 1996; Zanetti et al., 1996; Hungate et al., 1999; Edwards et al., 2006; Lam et al., 2012). These effects are strongest immediately after exposure to elevated $\mathrm{CO}_{2}\left(\mathrm{eCO}_{2}\right)$ (Hungate et al., 2004) and when other nutrients (especially phosphorus) are not limiting (Rogers et al., 2009). Elevated $\mathrm{CO}_{2}\left(\mathrm{eCO}_{2}\right)$ can promote $\mathrm{BNF}$ via several mechanisms, including larger numbers of $\mathrm{N}_{2}$ fixing symbiotic bacteria in the rhizosphere (Schortemeyer et al., 1996), increased numbers of nodules which house $\mathrm{N}_{2}$ fixing rhizobia bacteria (Ryle and Powell, 1992) and enhanced nitrogenase activity (Norby, 1987). Broadly speaking, $\mathrm{eCO}_{2}$ allows legumes to increase rates of photosynthesis and allocate more carbon belowground to support increased root nodulation and therefore BNF (Aranjuelo et al., 2014).

Researchers are becoming increasingly aware of the importance of testing multiple environmental change factors because they are predicted to occur concurrently and often have either synergistic or antagonistic impacts on one another (Robinson et al., 2012; Johnson and Jones, 2017). Climate models predict, for instance, that air temperatures will increase in tandem with increases in atmospheric $\mathrm{CO}_{2}$ and warmer temperature may negate any positive impacts of $\mathrm{eCO}_{2}$ on plant growth (Newman et al., 2011). This may be particularly true in legume systems because higher temperatures can have inhibitory effects on BNF due to the relatively low tolerance of $\mathrm{N}_{2}$-fixing bacteria to higher temperatures (Zahran, 1999; Whittington et al., 2013; Aranjuelo et al., 2014). The optimal temperature for root nodule symbiosis for temperate legumes is thought to be around $15-25^{\circ} \mathrm{C}$, above which detrimental effects can become evident (Aranjuelo et al., 2014). Elevated temperature (eT) can directly hinder the development and functionality of root nodulation and accelerate nodule senescence (Piha and Munns, 1987; Aranjuelo et al., 2006). In addition, eT can inhibit nodulation via plant-mediated mechanisms, including reduced root hair formation, fewer nodulation sites and poorer adherence of bacteria to root hairs (Hungria and Franco, 1993; Hungria and Vargas, 2000; Aranjuelo et al., 2014).

Soil conditions play an important role in determining the extent to which $\mathrm{eCO}_{2}$ and $\mathrm{eT}$ affect root nodulation in legumes (Aranjuelo et al., 2014). Several studies report that supplementation of soil silicon (Si) levels promotes growth in legumes (Horst and Marschner, 1978; Miyake and Takahashi, 1985; Guo et al., 2006; Johnson et al., 2017), though we know less about the functional role of $\mathrm{Si}$ in legumes compared to other plant families such as the Poaceae (Epstein, 1999; Cooke and Leishman, 2011). Moreover, Si supplementation can increase rates of root nodulation and symbiosis with nitrogen fixing bacteria (Nelwamondo and Dakora, 1999; Mali and Aery, 2008). However, how these positive effects of Si on nodulation are affected by $\mathrm{eCO}_{2}$ or $\mathrm{eT}$, alone or in combination, have not yet been addressed. If Si could maintain nodulation rates under future climate change scenarios, such as
eT, which usually decrease it, then such supplementation could be important in the mitigation of climate change impacts on agriculture.

While rhizobial colonization promotes legume growth and vigor, this improved host quality can also increase susceptibility to belowground (Quinn and Hower, 1986; Gerard, 2001; Johnson and McNicol, 2010) and aboveground insect herbivores (Dean et al., 2009, 2014; Kempel et al., 2009; Katayama et al., 2010; Whitaker et al., 2014). Beneficial effects of rhizobia on herbivores most likely arise through increased provision of nitrogen, which is frequently limiting in insect herbivore diets (Mattson, 1980). Increased provision of nitrogen may, however, allow plants to invest in plant defenses with negative impacts on herbivores (Pineda et al., 2010; Brunner et al., 2015). While Si supplementation usually increases plant resistance to herbivores (mainly reported in the Poaecae; Reynolds et al., 2009), it may also indirectly increase susceptibility to herbivores via increases in legume growth and nutritional quality (Johnson et al., 2017).

The objective of this study was to determine how $\mathrm{eCO}_{2}$ and eT, acting alone and in combination, affected root nodulation and plant growth in Medicago sativa in untreated $(\mathrm{Si}-)$ and $\mathrm{Si}$ supplemented $(\mathrm{Si}+)$ soil. We additionally aimed to establish whether these factors affected the abundance and colonization success of an insect herbivore (the aphid Acyrthosiphon pisum). We hypothesized that $\mathrm{eCO}_{2}$ increases growth and root nodulation in $M$. sativa but eT negates these effects. Si supplementation increases nodulation, even under $\mathrm{eT}$, and therefore maximizes plant growth regardless of $\mathrm{CO}_{2}$ and temperature conditions. We hypothesized that aphid abundance would be positively linked to plant growth and nodulation, whether driven by $\mathrm{Si}$ supplementation or changes in $\mathrm{CO}_{2}$ and temperature conditions.

\section{MATERIALS AND METHODS}

\section{Insect Cultures and Plant Material}

Four A. pisum cultures were established from a single parthenogenetic adult female collected from a pasture containing grasses and legumes, including lucerne, at the Hawkesbury Campus of the Western Sydney University, Penrith, NSW, Australia (latitude -33.608847, longitude 150.747016). Cultures were maintained on propagated lucerne ( $M$. sativa L.) plants (Sequel cultivar) in each of the four $\mathrm{CO}_{2}$ and temperature combinations (conditions below) for at least six generations (c. 7 weeks) prior to the experiment. For the experiment, M. sativa (Sequel) were grown from seed (Heritage Seeds Pty, Adelaide, SA, Australia) in glasshouse rooms receiving supplemental light (15:9 light:dark) under the same conditions. Plants were grown in $70 \mathrm{~mm}$ diameter pots containing c. $700 \mathrm{~g}$ of soil excavated from the Hawkesbury campus of Western Sydney University (location as above). The soil is typified as lowfertility sandy loam in the Clarendon Formation (Chromosol) (Barton et al., 2010), which has low bioavailable Si content of 10-17 $\mathrm{mg} \mathrm{kg}^{-1}$ (Johnson et al., 2017). 


\section{Growth Conditions and Experimental Procedures}

Eighty lucerne plants were grown in each of four $\mathrm{CO}_{2}$ and temperature-controlled glasshouse chambers $(320$ plants in total) using a fully factorial design of ambient $\mathrm{CO}_{2}\left(\mathrm{aCO}_{2}\right.$;

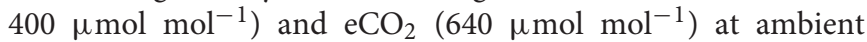
(aT) and elevated temperature (ambient $+4^{\circ} \mathrm{C}$; eT). aT was set at $26 / 18^{\circ} \mathrm{C}$ day/night representing the average daily temperature (November to May) over the past 30 years for Richmond, NSW, Australia (Australian Bureau of Meteorology). eT $\left(30 / 22^{\circ} \mathrm{C}\right.$ day/ night) replicated the maximum predicted temperature increase for this region within this century (CSIRO, 2007-2016). Environmental conditions were monitored continuously throughout the experiment and temperature readings were verified with portable temperature loggers. To minimize 'chamber effects' associated with using four chambers, plants were circulated within each chamber every 5 days (apart from when plants were inoculated with aphids to avoid dislodgement of the insects) and chambers were swapped every c. 10 days by transferring plants between chambers and adjusting the environmental conditions accordingly. While this does not eliminate pseudoreplication, using this approach in these chambers has provided matching empirical results to fully replicated experiments, whether using multiple chamber replicates or multiple experimental runs (Johnson et al., 2016b).

Plants were irrigated with c. $70 \mathrm{ml}$ of tap water (Si $3 \mathrm{ppm}$ ) three times a week. After growing for a further 2 weeks, half (40) of the plants continued to receive tap water ( $\mathrm{Si}-$ plants or $\mathrm{Si}-$ soil hereafter) at the same intervals while the other half (selected at random) received $70 \mathrm{ml}$ of $500 \mathrm{mg} \mathrm{l}^{-1}$ soluble silica in the form of $\mathrm{NaSiO}_{3} .9 \mathrm{H}_{2} \mathrm{O}$ three times a week ( $\mathrm{Si}+$ plants or $\mathrm{Si}+$ soil hereafter). When plants were 6 weeks old, 20 of the plants receiving the Si supplementation and 20 of the plants receiving tap water (selected at random) were inoculated with two teneral adult $A$. pisum. White mesh (organza) bags $(125 \mathrm{~mm} \times 170 \mathrm{~mm}$ ) were applied tightly around the rim of all pots confining aphids to their allocated plants. After 2 weeks, bags were removed aphids counted (including colonization success; at least one aphid being present). Plants were cleaned free of soil with water and the number of active (pink) root nodules quantified. Maximum rooting depth was also quantified to provide a rudimentary measure of nodule density in order to give an indication as whether changes in nodule abundance were a function of root growth or nodule density on the roots (i.e., nodules per unit of root growth). Plants were freeze dried for $48 \mathrm{~h}$ and weighed. Leaves were separated from the stems and ball-milled to a fine powder prior to analysis for Si concentrations.

\section{Foliar Si Analysis}

It was necessary to pool foliar samples (2-3 plants per sample), giving nine replicates of each treatment combination ( $\mathrm{CO}_{2}$, temperature, $\mathrm{Si}$ application and aphid inoculation). Foliar Si concentrations were analyzed with X-ray fluorescence spectrometry using the method described by Reidinger et al. (2012). In summary, plant material was ground to a fine powder and pressed into $13 \mathrm{~mm}$-diameter pellets. Foliar Si concentration was determined using a Niton XL3t XRF analyzer (Thermo Fisher Scientific, Inc., Waltham, MA, United States), for a measurement time of $30 \mathrm{~s}$. Results we expressed as foliar Si concentration (as \% of dry mass), calibrated against plant-certified reference material of known Si content (Garbuzov et al., 2011).

\section{Statistical Analysis}

Goodness-of-fit tests, using the 'goodfit' function in the vcd package (Friendly, 2000), were employed to determine which distributions best described the data. Plant dry mass and nodule density were transformed (logarithm and square-root, respectively) prior to analysis to meet model assumptions and give residual diagnostic plots which fitted a normal distribution and showed least heteroscedasticity. Plant dry mass and nodule density were analyzed using analysis of variance with $\mathrm{CO}_{2}$, temperature, aphid presence, and Si supplementation included as fixed effects individually and in interaction with one another. Root nodule counts and aphid abundance were analyzed with generalized linear models with negative binomial error structures and log-link function using the same configuration of fixed effects as above. Aphid colonization success was analyzed in the same way but with binomial error structure and logit link function. Statistical tests of plant mass and nodulation were conducted on data collectively, before repeating the tests separately for $\mathrm{Si}-$ and $\mathrm{Si}+$ plants since there were significant interactions between $\mathrm{Si}$ treatment and environmental treatments. Where non-significant effects were observed in full models (i.e., all factors included), non-significant factors were removed to determine whether this affected model inferences with more parsimonious models (e.g., fewer multi-way interaction terms were included in the model) see Supplementary Table S1. All analysis was conducted in the R statistical package.

\section{RESULTS}

Plant growth was stimulated by $\mathrm{eCO}_{2}$ and $\mathrm{Si}$ supplementation by 41 and 93\%, respectively (Figure 1 and Table 1). In contrast, eT and aphid presence depressed plant growth by 13 and $17 \%$, respectively (Figure $\mathbf{1}$ and Table 1). Temperature depressed plant growth in $\mathrm{Si}$ - soil (Figure 1A), but not in $\mathrm{Si}+$ soil (Figure 1B), though there was an interactive effect of $\mathrm{CO}_{2}$ and temperature in the latter, with $\mathrm{eCO}_{2}$ promoting plant growth more at $\mathrm{eT}$ than under aT conditions (Figure 1B).

Root nodulation increased when plants grew under $\mathrm{eCO}_{2}$ $(+27 \%)$ and $\mathrm{Si}+$ conditions $(+50 \%)$ (Figure 2 and Table 1), but eT caused significant declines in nodulation $(-32 \%)$. In $\mathrm{Si}-$ soil, root nodulation patterns generally mirrored changes in plant growth (Figures 1A, 2A, respectively). Levels of root nodulation were universally high in plants growing in $\mathrm{Si}+$ soil and other factors $\left(\mathrm{CO}_{2}\right.$, temperature, and aphid presence) no longer had significant impacts (Figure 2B). This was particularly true for the negative impacts of $\mathrm{eT}$, which was reversed under $\mathrm{Si}+$ conditions, reflected by the significant interaction of these treatments (Figure 2 and Table 1). Our rudimentary estimate of nodule density (nodules per unit of root depth) suggested this was not affected by $\mathrm{CO}_{2}$ (other than the weak interaction 


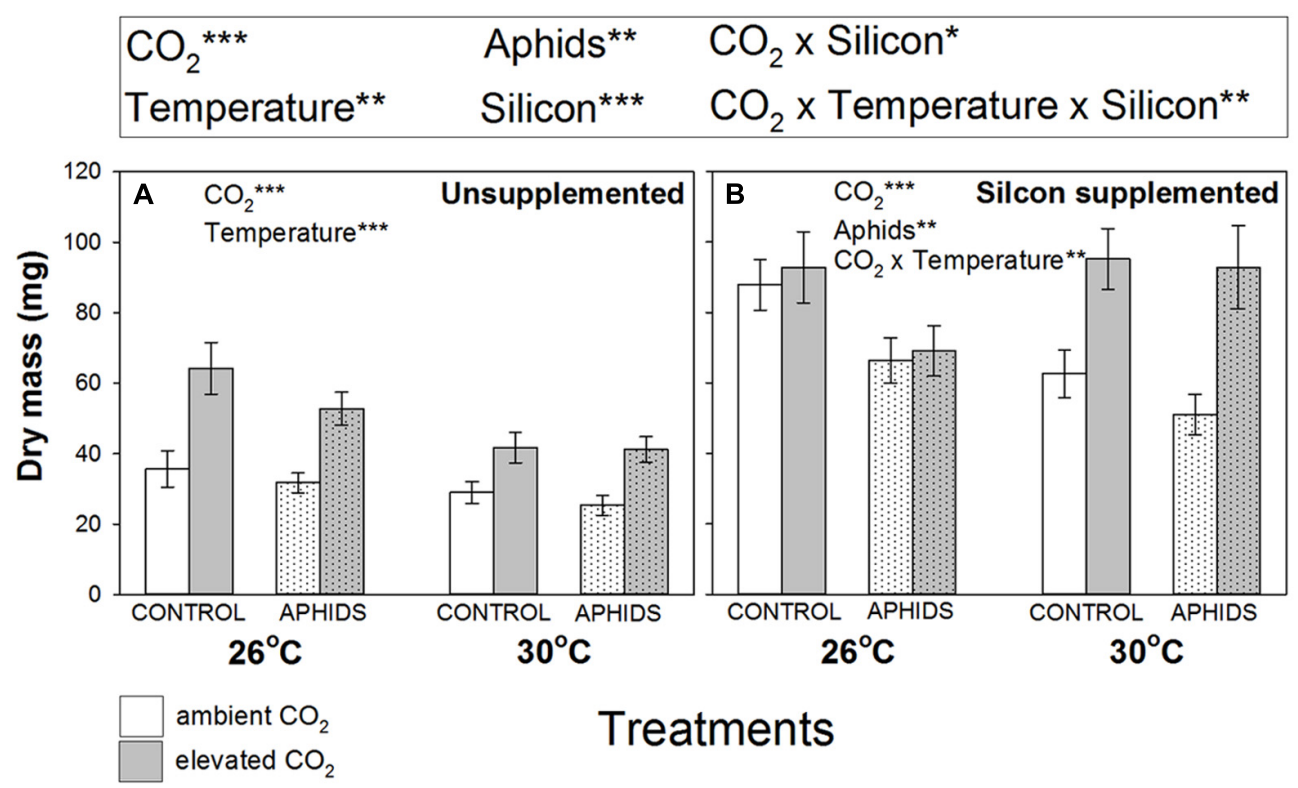

FIGURE 1 | Impacts of $\mathrm{CO}_{2}$, temperature and aphid presence on dry mass of Medicago sativa when growing in (A) non-supplemented and (B) Si supplemented soil. Mean values \pm standard error shown $(N=20)$ with statistically significant effects indicated $* P<0.05$, ${ }^{* *} P<0.01$, and $* * * P<0.001$. Significant factors for the whole experiment given in the upper panel (see Table $\mathbf{1}$ for full results) and for $\mathrm{Si}-$ and $\mathrm{Si}+$ plants separately in the respective graphical panels.

described below) but declined by $25 \%$ under eT (Supplementary Figure S1 and Supplementary Table S1). Nodule density increased (c. $+45 \%)$ under $\mathrm{Si}+$ conditions and, like nodule abundance, there was a significant interaction between Si treatment and temperature, whereby negative effects of $\mathrm{eT}$ were reversed under $\mathrm{Si}+$ conditions (Supplementary Figure S1 and Supplementary
Table S1). There was a very weak interaction between Si, aphids, and $\mathrm{CO}_{2}$.

$\mathrm{Si}$ concentration in the foliage was unaffected by $\mathrm{CO}_{2}$, temperature and aphid presence, though unexpectedly there was a small but significant decline in foliar Si concentrations when growing in $\mathrm{Si}+$ soil (Figure 3 and Table $\mathbf{1}$ ).

TABLE 1 | Results of statistical tests examining the effects of $\mathrm{CO}_{2}$, temperature (Temp), aphid presence and Si supplementation (Si) on plant growth, root nodulation, and foliar Si concentrations.

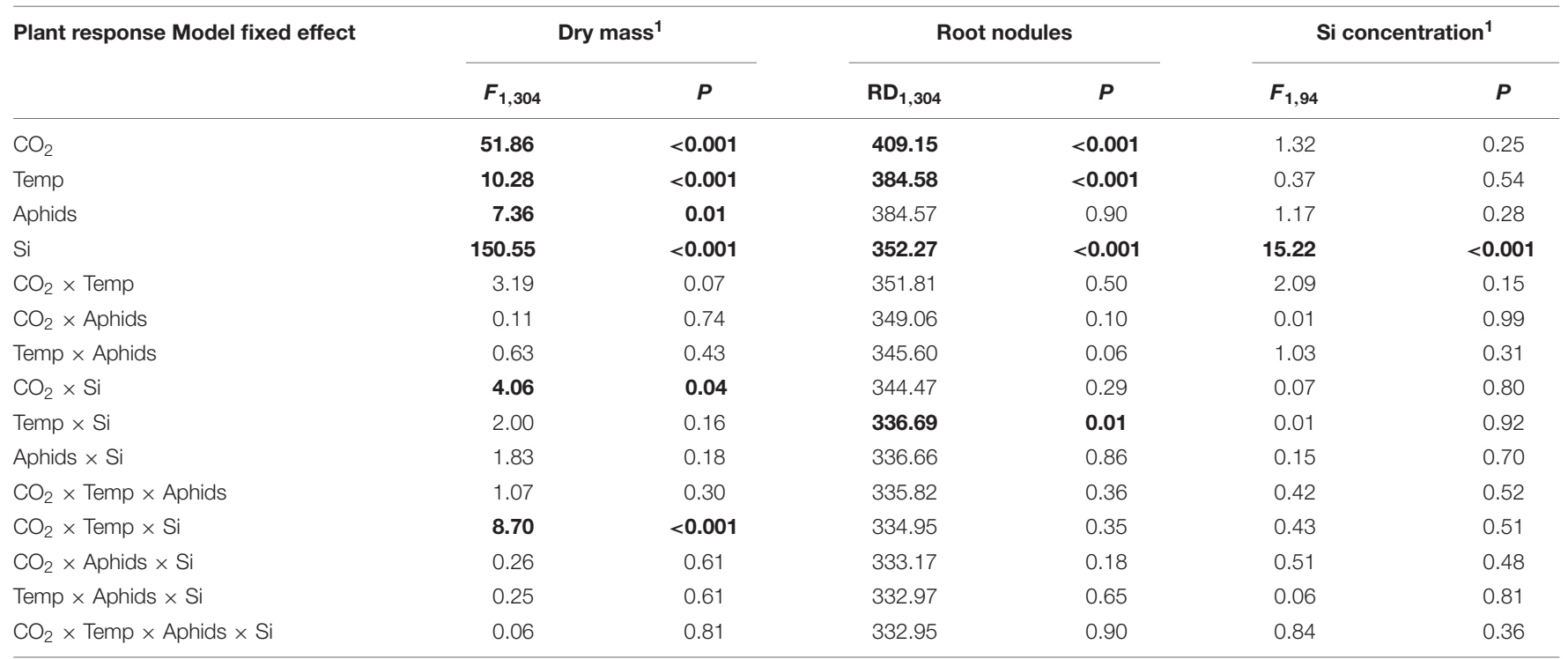

Statistically significant $(P<0.05)$ factors indicated in bold with Fisher's $(F)$ or residual deviation $(R D)$ given depending on the models used. Analysis conducted on transformed data as indicated.

${ }^{1}$ Log transformed. Degrees of freedom in each column apply to all effects. 


\section{$\mathrm{CO}_{2}^{* *}$ Temperature ${ }^{* * *}$ Silicon ${ }^{* * *}$ Temperature $x$ Silicon*}

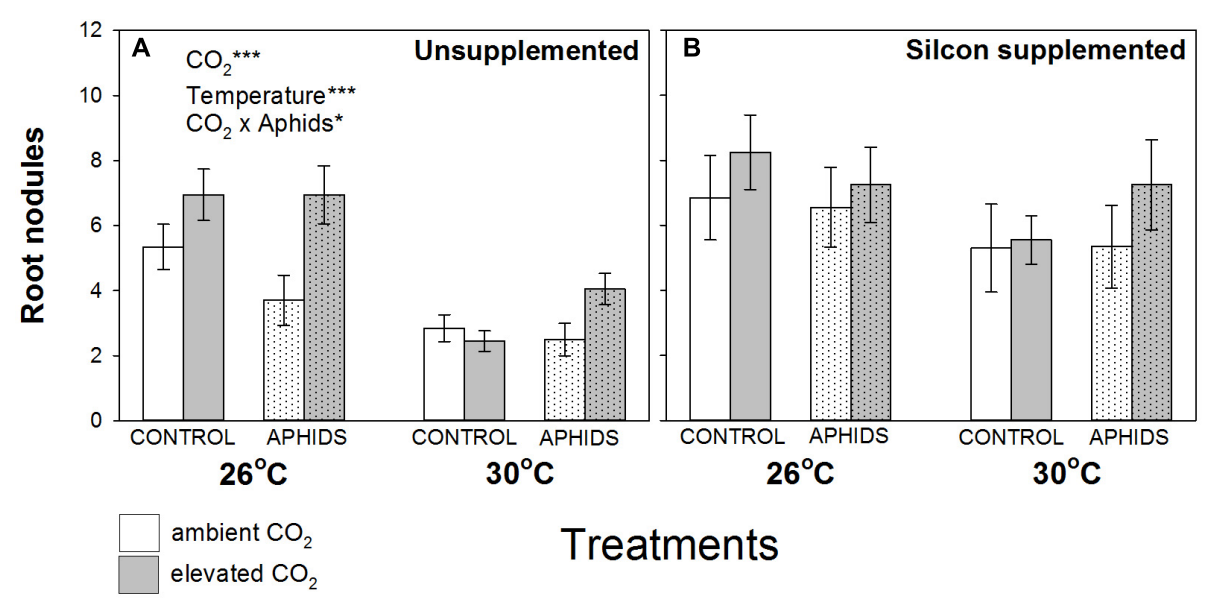

FIGURE 2 | Impacts of $\mathrm{CO}_{2}$, temperature and aphid presence on root nodulation (number per plant) of $M$. sativa when growing in (A) non-supplemented and (B) Si supplemented soil. Mean values \pm standard error shown $(N=20)$ with statistically significant effects indicated ${ }^{*} P<0.05$, ${ }^{* *} P<0.01$, and ${ }^{* * *} P<0.001$. Significant factors shown as per Figure 1 legend.

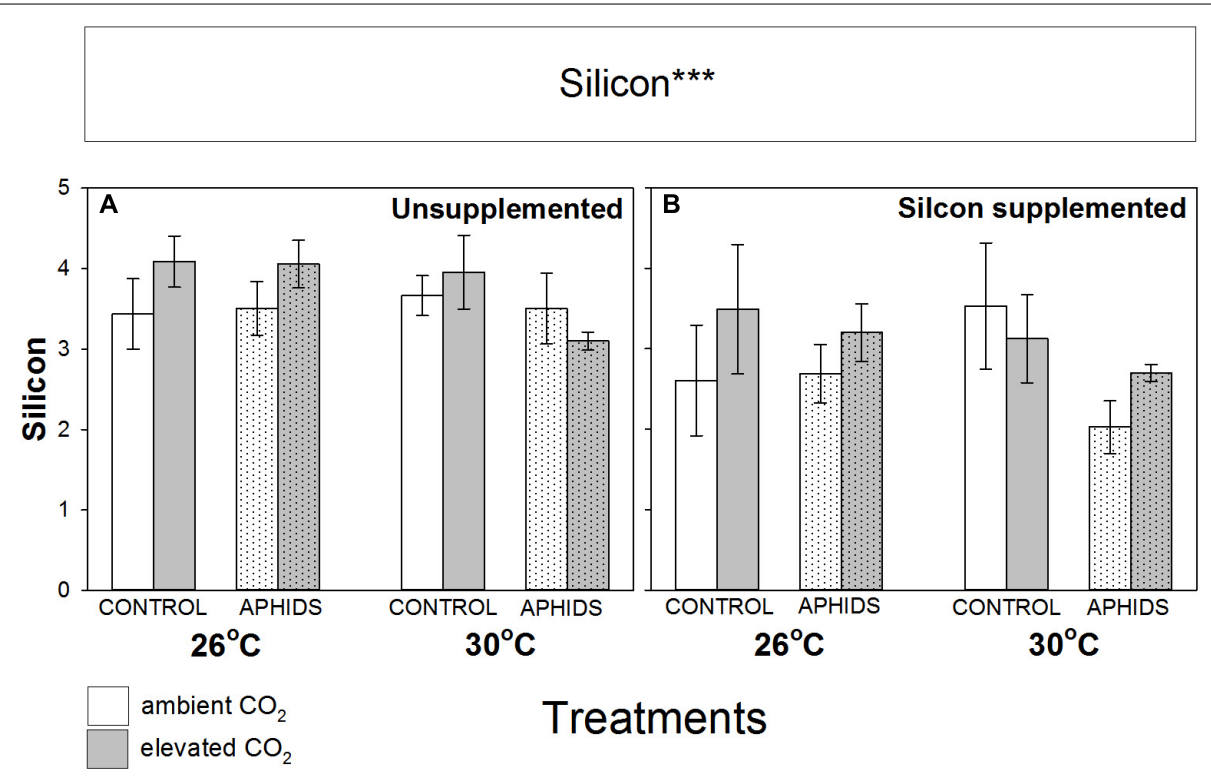

FIGURE 3 | Impacts of $\mathrm{CO}_{2}$, temperature and aphid presence on Si concentrations of $M$. sativa foliage (\% dry mass) when growing in (A) non-supplemented and (B) Si supplemented soil. Mean values \pm standard error shown $(N=9)$ with statistically significant effects indicated $* * * P<0.001$. Significant factors shown as per Figure 1 legend.

Aphid abundance was not significantly affected by $\mathrm{eCO}_{2}$ (Figure 4), although colonization success increased by $14 \%$ under $\mathrm{eCO}_{2}$ (Table 2). In contrast, eT caused substantial declines $(-65 \%)$ in aphid abundance and reduced their ability to colonize plants, falling by 48 and $43 \%$ on $\mathrm{Si}-$ and $\mathrm{Si}+$ plants, respectively (Table 2). Aphid populations at eT were similar regardless of Si treatments. In short, aphid abundance was always lowest at $30^{\circ} \mathrm{C}$ and $\mathrm{Si}$ promotion of plant growth and nodulation was decoupled from aphid performance, such that $\mathrm{Si}+$ conditions led to increased nodulation (and potentially BNF) without increasing aphid numbers.

The key findings of this study are summarized in Figure 5 which held true when non-significant terms were dropped from models for parsimony (see Supplementary Table S2). Figures 5A-C shows how aphid abundance mirrors patterns of nodulation and plant growth in non-supplemented 


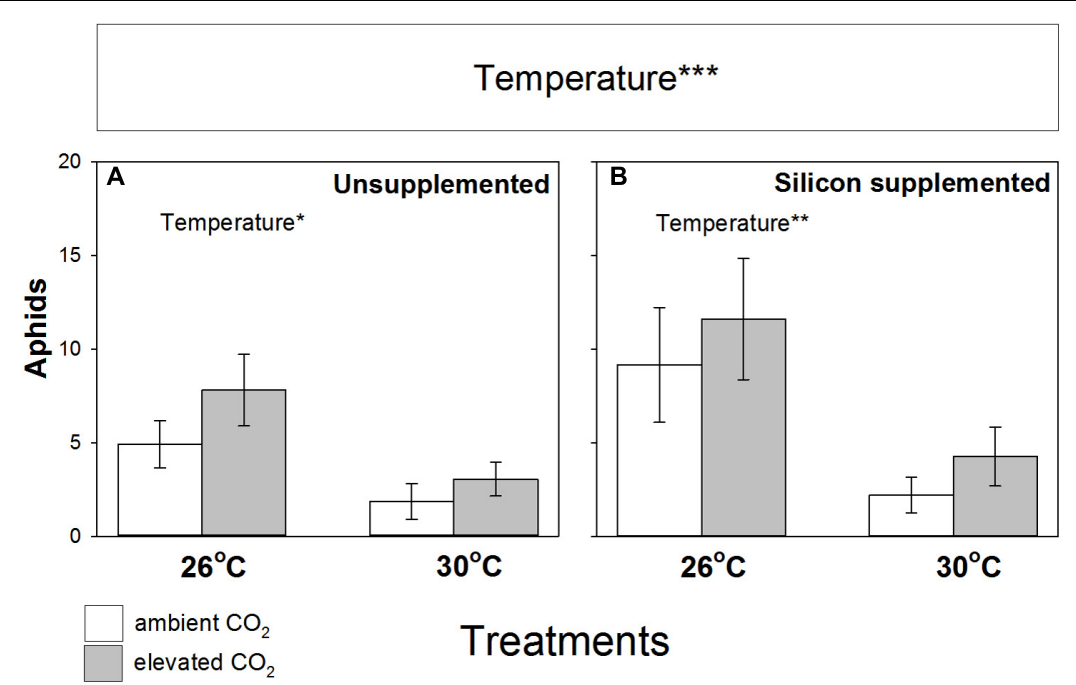

FIGURE 4 | Impacts of $\mathrm{CO}_{2}$ and temperature on aphid (Acyrthosiphon pisum) abundance (number per plant) when feeding on $M$. sativa plants growing in (A) non-supplemented and (B) Si supplemented soil. Mean values \pm standard error shown $(N=20)$ with statistically significant effects indicated $* * * P<0.001$. Significant factors shown as per Figure 1 legend.

soils, but this becomes decoupled in $\mathrm{Si}+$ soils, where $\mathrm{Si}$ supplementation restores the fertilizing effects of $\mathrm{eCO}_{2}$ on $M$. sativa at higher temperatures without affecting aphid populations.

\section{DISCUSSION}

Results from this study suggest that $\mathrm{Si}$ supplementation may mitigate the negative impacts of eT on plant growth in $M$. sativa which was potentially due to stimulation of root nodulation, despite the reduction in nodulation at higher temperatures reported in previous studies (e.g., Ryalls et al., 2013b). Even more advantageously, this increased nodulation did not increase susceptibility to an aphid pest at $\mathrm{eT}$, which had previously been observed for $\mathrm{Si}$ induced increases in nodulation at ambient temperatures (Johnson et al., 2017).

TABLE 2 | Results of statistical tests examining the effects of $\mathrm{CO}_{2}$, temperature and $\mathrm{Si}$ supplementation on aphid abundance and colonization success.

\begin{tabular}{lccccc}
\hline $\begin{array}{l}\text { Plant response } \\
\text { Model fixed effect }\end{array}$ & \multicolumn{2}{c}{ Aphid abundance } & & \multicolumn{2}{c}{ Aphid colonization } \\
\cline { 2 - 3 } \cline { 5 - 6 } & $\mathbf{R D}_{\mathbf{1 , 1 5 9}}$ & $\boldsymbol{P}$ & & $\mathbf{R D}_{\mathbf{1 , 1 5 9}}$ & $\boldsymbol{P}$ \\
\hline $\mathrm{CO}_{2}$ & 177.62 & 0.16 & & $\mathbf{2 1 5 . 2 3}$ & $\mathbf{0 . 0 2 6}$ \\
$\mathrm{Temp}$ & $\mathbf{1 6 2 . 3 9}$ & $<\mathbf{0 . 0 0 1}$ & & $\mathbf{1 9 7 . 2 1}$ & $<\mathbf{0 . 0 0 1}$ \\
$\mathrm{Si}$ & 160.42 & 0.16 & & 196.16 & 0.30 \\
$\mathrm{CO}_{2} \times \mathrm{Temp}$ & 160.24 & 0.68 & & 195.90 & 0.61 \\
$\mathrm{CO}_{2} \times \mathrm{Si}$ & 160.24 & 0.93 & & 195.90 & 0.99 \\
$\mathrm{Temp} \times \mathrm{Si}$ & 160.03 & 0.65 & & 105.89 & 0.95 \\
$\mathrm{CO}_{2} \times$ Temp $\times \mathrm{Si}$ & 159.91 & 0.73 & & 194.50 & 0.24 \\
\hline
\end{tabular}

Statistically significant $(P<0.05)$ indicated in bold with residual deviation $(R D)$ given.
Aphid abundance was strongly suppressed by eT and this most likely explains why aphids did not benefit from increases in plant growth and nodulation that arose under $\mathrm{Si}+$ conditions under eT. While aphid numbers often increase with higher temperatures via faster development and increased fecundity, this increase ceases abruptly over a certain temperature threshold because of the adverse effects on, for example, embryo development and maturation (Ryalls and Harrington, 2017). This temperature threshold depends on species, aphid biotype, and geographical region (Awmack and Leather, 2007). A. pisum has adapted to the warmer climate of Australia since introduction in the 1970s (Ryalls et al., 2013a). Some populations are able to function at temperatures above $35^{\circ} \mathrm{C}$, although their optimum temperature is said to be c. $20-25^{\circ} \mathrm{C}$ (Ryalls, 2016) and temperatures above $28^{\circ} \mathrm{C}$ are likely to reduce aphid growth and development (Bieri et al., 1983; Lamb and MacKay, 1988; Mackay et al., 1993). Aphid biotypes with certain secondary bacterial endosymbionts may cope better with higher temperatures, however, since there have been several reports of endosymbionts alleviating the effects of heat stress (Montllor et al., 2002; Russell and Moran, 2005; Dunbar et al., 2007). To our knowledge, studies have not yet addressed how bacterial endosymbionts might change in response to $\mathrm{eCO}_{2}$ and $\mathrm{eT}$ but endosymbionts could partially facilitate adaptation to climate and atmospheric change (Sun et al., 2016; Ryalls and Harrington, 2017).

Several studies using temperature gradient greenhouses have examined the impacts of $\mathrm{eCO}_{2}$ and eT on legume performance, including root nodulation (Aranjuelo et al., 2006, 2008; Erice et al., 2006, 2007). These studies report a general trend for $\mathrm{eCO}_{2}$ promoting nodulation, but only at the elevated experimental temperatures. This was probably because the elevated temperature range used in experiments (c. $24^{\circ} \mathrm{C}$; Aranjuelo et al., 2008) was still within the optimal range $\left(19-25^{\circ} \mathrm{C}\right)$ for nodulation in temperate legumes, so inhibitory 


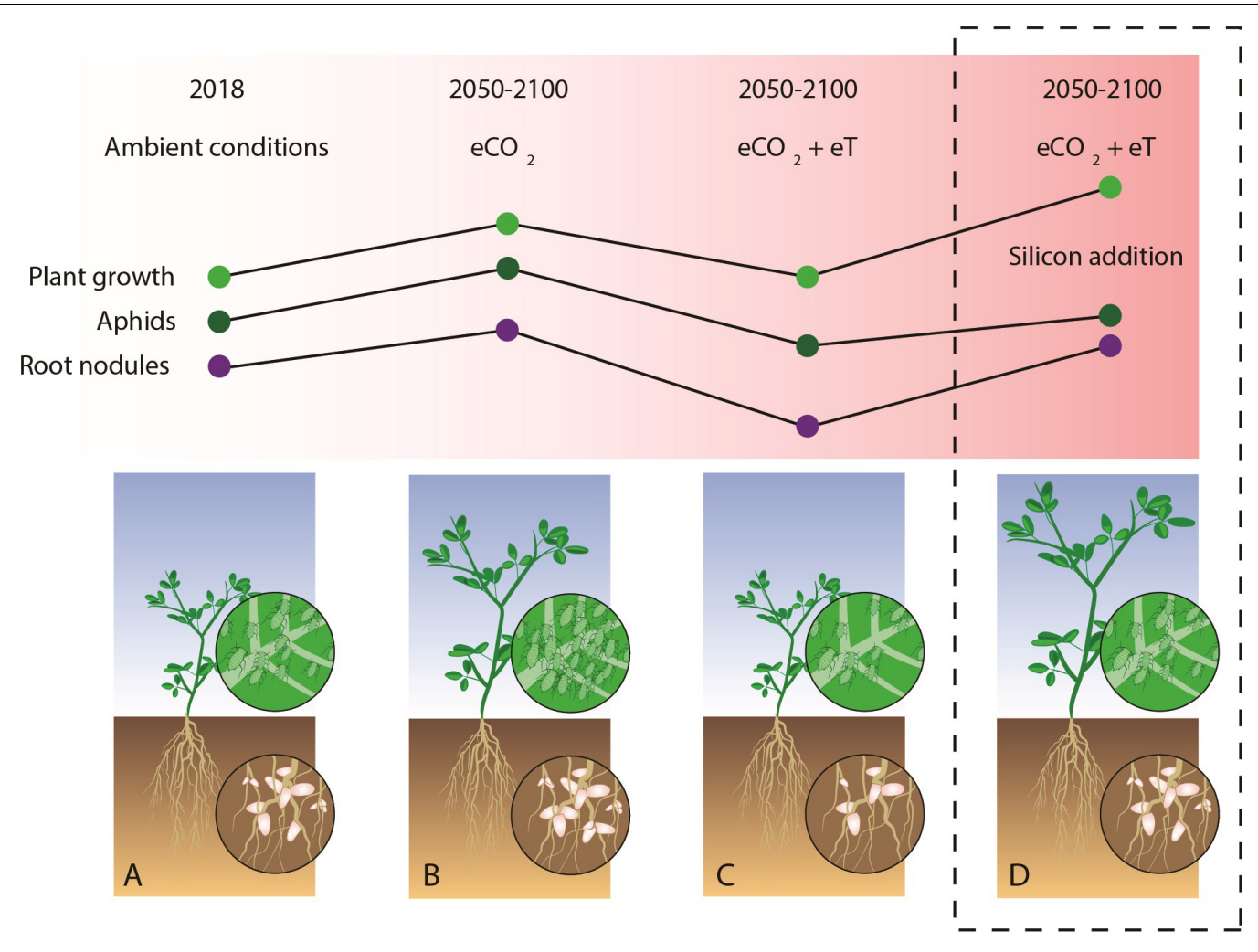

FIGURE 5 | Graphical summary showing how Si supplementation affects $M$. sativa growth, root nodulation and susceptibility to $A$. pisum in current and predicted changes to the climate and atmosphere. Compared with ambient $\mathrm{CO}_{2}$ and temperature conditions (A), eCO $\mathrm{C}_{2}$ had beneficial effects on plant growth and nodulation (B), but these were negated when acting in combination with predicted increases in temperature (C). Si supplementation (D) restored root nodulation to comparable levels as those seen under $\mathrm{eCO}_{2}$ conditions (without warming) and stimulated plant growth beyond this. Aphid responses were decoupled from changes in nodulation and growth with Si supplementation.

effects of temperature on nodulation wouldn't necessarily have occurred (Aranjuelo et al., 2014). When temperature was elevated beyond $25-30^{\circ} \mathrm{C}$, root nodulation in $M$. sativa has been reported to decrease by $22 \%$ under ambient $\mathrm{CO}_{2}\left(\mathrm{aCO}_{2}\right)$ and by $56 \%$ under eCO 2 (Ryalls et al., 2013b).

Despite increasing evidence that the effects of $\mathrm{eCO}_{2}$ are often modified by eT, and vice versa, comparatively few studies manipulate both factors in tandem (Robinson et al., 2012). In the present study we established that positive impacts of $\mathrm{eCO}_{2}$ on plant traits were not seen to the same extent when eT conditions were applied. This study therefore lends support to the notion that, wherever feasible, multiple environmental factors should be tested (Newman et al., 2011; Lindroth and Raffa, 2016). Crucially, Si supplementation had consistently stronger impacts on plant traits across a range of environmental conditions and regardless of whether plants were challenged by herbivores.

A counterintuitive finding of the study was that $\mathrm{Si}$ supplementation actually reduced concentrations of $\mathrm{Si}$ in the foliage. Si may have promoted plant growth to such an extent that Si became 'diluted' in foliage, or else had not had time to accumulate in plant tissues over the duration of the study. A similar trend in foliar Si was previously observed in this system however, associated with rapid plant growth, increases in root nodulation and synthesis of amino acids (Johnson et al.,
2017). In addition to any increased nutritional value, the lower concentrations of $\mathrm{Si}$ in foliage of $\mathrm{Si}+$ plants may explain why $\mathrm{Si}$ supplementation did not increase plant resistance to aphids.

Our results demonstrate conclusively the benefits of $\mathrm{Si}$ supplementation for root nodulation: root nodule abundance was always increased in plants growing in $\mathrm{Si}+$ soil and other factors, whether $\mathrm{CO}_{2}$, temperature and aphid presence no longer had significant impacts on nodule abundance. The mechanisms by which $\mathrm{Si}$ is so effective at promoting nodulation are not well-understood, but could include changes in soil conditions, increased root growth (and potential invasion sites), higher abundance of bacteroids and symbiosomes, together with the synthesis of compounds that upregulate nodulation genes (as discussed by Johnson et al., 2017). The increased nodule density reported in the present study tentatively suggests that greater nodule abundance was not merely a function of increased root growth. Further work is needed, but $\mathrm{Si}$ could provide a useful tool for mitigating some of the negative impacts of climate change on crop production - in this instance maintaining nodulation rates of $M$. sativa in warmer climates. Moreover, other studies suggest $\mathrm{Si}$ could redress negative effects of $\mathrm{eCO}_{2}$ on plantherbivore interactions. For example, herbivore damage to roots of sugarcane was exacerbated under $\mathrm{eCO}_{2}$ conditions, 
but application of Si reversed these effects and stimulated crop growth (Frew et al., 2017). Intervention strategies could include targeted application of Si (e.g., furnace slag), selection of plant lines that naturally take up large amounts of Si (McLarnon et al., 2017) and remediation of soils deficient in bioavailable Si (silicic acid) (Guntzer et al., 2012; Johnson et al., 2016a).

\section{AUTHOR CONTRIBUTIONS}

SJ, JR, AF, and AG: conceived the experimental design; SJ, JR, $\mathrm{AF}$, and $\mathrm{AG}$ : acquired and processed data with $\mathrm{SH}$ undertaking Si analysis; JR: analyzed the data and all authors contributed to the interpretation and drafting of the manuscript.

\section{REFERENCES}

Aranjuelo, I., Arrese-Igor, C., and Molero, G. (2014). Nodule performance within a changing environmental context. J. Plant Physiol. 171, 1076-1090. doi: 10.1016/ j.jplph.2014.04.002

Aranjuelo, I., Irigoyen, J. J., Pérez, P., Martínez-Carrasco, R., and SánchezDíaz, M. (2006). Response of nodulated alfalfa to water supply, temperature and elevated $\mathrm{CO}_{2}$ : productivity and water relations. Environ. Exp. Bot. 55, 130-141. doi: 10.1016/j.envexpbot.2004.10.007

Aranjuelo, I., Irigoyen, J. J., Sánchez-Díaz, M., and Nogués, S. (2008). Carbon partitioning in $\mathrm{N}_{2}$ fixing Medicago sativa plants exposed to different $\mathrm{CO}_{2}$ and temperature conditions. Funct. Plant Biol. 35, 306-317. doi: 10.1071/fp07296

Awmack, C., and Leather, S. R. (2007). "Growth and development," in Aphids as Crop Pests, eds H. F. Van Emden and R. Harrington (Wallingford, UK: CABI), 135-151. doi: 10.1079/9780851998190.0135

Barton, C. V. M., Ellsworth, D. S., Medlyn, B. E., Duursma, R. A., Tissue, D. T., Adams, M. A., et al. (2010). Whole-tree chambers for elevated atmospheric $\mathrm{CO}_{2}$ experimentation and tree scale flux measurements in south-eastern Australia: the Hawkesbury Forest Experiment. Agric. For. Meteorol. 150, 941-951. doi: 10.1016/j.agrformet.2010.03.001

Bieri, M., Baumgärtner, J., Bianchi, G., Delucchi, V., and von Arx, R. (1983). Development and fecundity of pea aphid (Acyrthosiphon pisum Harris) as affected by constant temperatures and by pea varieties. Mitt. Schweiz. Entomol. Ges. 56, 163-171. doi: 10.5169/seals-402070

Brunner, S. M., Goos, R. J., Swenson, S. J., Foster, S. P., Schatz, B. G., Lawley, Y. E., et al. (2015). Impact of nitrogen fixing and plant growth-promoting bacteria on a phloem-feeding soybean herbivore. Appl. Soil Ecol. 86, 71-81. doi: 10.1016/j.apsoil.2014.10.007

Cooke, J., and Leishman, M. R. (2011). Is plant ecology more siliceous than we realise? Trends Plant Sci. 16, 61-68. doi: 10.1016/j.tplants.2010.10.003

CSIRO (2007-2016). Climate Change in Australia: Technical Report [Online]. Melbourne, Australia: CSIRO. Available: http://www.climatechangeinaustralia. gov.au/ [accessed November 10, 2017]

Dean, J. M., Mescher, M. C., and De Moraes, C. M. (2009). Plant-rhizobia mutualism influences aphid abundance on soybean. Plant Soil 323, 187-196. doi: 10.1007/s11104-009-9924-1

Dean, J. M., Mescher, M. C., and De Moraes, C. M. (2014). Plant dependence on rhizobia for nitrogen influences induced plant defenses and herbivore performance. Int. J. Mol. Sci. 15, 1466-1480. doi: 10.3390/ijms150 11466

Dunbar, H. E., Wilson, A. C. C., Ferguson, N. R., and Moran, N. A. (2007). Aphid thermal tolerance is governed by a point mutation in bacterial symbionts. PLoS Biol. 5:e96. doi: 10.1371/journal.pbio.0050096

Edwards, E. J., McCaffery, S., and Evans, J. R. (2006). Phosphorus availability and elevated $\mathrm{CO}_{2}$ affect biological nitrogen fixation and nutrient fluxes in a cloverdominated sward. New Phytol. 169, 157-167. doi: 10.1111/j.1469-8137.2005. 01568.x

Epstein, E. (1999). Silicon. Annu. Rev. Plant Physiol. Plant Mol. Biol. 50, 641-664. doi: 10.1146/annurev.arplant.50.1.641

\section{ACKNOWLEDGMENTS}

The authors are grateful to James Stockdale for conducting the Si analysis and the 2015 class of the Invertebrate Biology (300918) unit for assistance in conducting the experiment. This research was part of a Hawkesbury Institute for the Environment exchange program awarded to $\mathrm{SH}$ and SJ.

\section{SUPPLEMENTARY MATERIAL}

The Supplementary Material for this article can be found online at: https://www.frontiersin.org/articles/10.3389/fpls.2018.00202/ full\#supplementary-material

Erice, G., Irigoyen, J. J., Pérez, P., Martínez-Carrasco, R., and Sánchez-Díaz, M. (2006). Effect of elevated $\mathrm{CO}_{2}$, temperature and drought on photosynthesis of nodulated alfalfa during a cutting regrowth cycle. Physiol. Plant. 126, 458-468. doi: 10.1111/j.1399-3054.2006.00599.x

Erice, G., Irigoyen, J. J., Sánchez-Díaz, M., Avice, J.-C., and Ourry, A. (2007). Effect of drought, elevated $\mathrm{CO}_{2}$ and temperature on accumulation of $\mathrm{N}$ and vegetative storage proteins (VSP) in taproot of nodulated alfalfa before and after cutting. Plant Sci. 172, 903-912. doi: 10.1016/j.plantsci.2006. 12.013

Frew, A., Allsopp, P. G., Gherlenda, A., and Johnson, S. N. (2017). Increased herbivory under elevated atmospheric carbon dioxide concentrations is reversed by silicon-based plant defences J. Appl. Ecol. 54, 1310-1319. doi: 10.1111/1365-2664.12822

Friendly, M. (2000). Visualizing Categorical Data. Cary, NC: SAS Institute.

Garbuzov, M., Reidinger, S., and Hartley, S. E. (2011). Interactive effects of plantavailable soil silicon and herbivory on competition between two grass species. Ann. Bot. 108, 1355-1363. doi: 10.1093/aob/mcr230

Gerard, P. J. (2001). Dependence of Sitona lepidus (Coleoptera: Curculionidae) larvae on abundance of white clover Rhizobium nodules. Bull. Entomol. Res. 91, 149-152. doi: 10.1079/BER200076

Guntzer, F., Keller, C., and Meunier, J. D. (2012). Benefits of plant silicon for crops: a review. Agron. Sust. Dev. 32, 201-213. doi: 10.1007/s13593-011-0039-8

Guo, Z. G., Liu, H. X., Tian, F. P., Zhang, Z. H., and Wang, S. M. (2006). Effect of silicon on the morphology of shoots and roots of alfalfa (Medicago sativa). Aust. J. Exp. Agric. 46, 1161-1166. doi: 10.1071/ea05117

Horst, W. J., and Marschner, H. (1978). Effect of silicon on manganese tolerance of bean plants (Phaseolus vulgaris L.). Plant Soil 50, 287-303. doi: 10.1007/ bf02107179

Hungate, B. A., Dijkstra, P., Johnson, D. W., Hinkle, C. R., and Drake, B. G. (1999). Elevated $\mathrm{CO}_{2}$ increases nitrogen fixation and decreases soil nitrogen mineralization in Florida scrub oak. Glob. Change Biol. 5, 781-789. doi: 10.1046/ j.1365-2486.1999.00275.x

Hungate, B. A., Stiling, P. D., Dijkstra, P., Johnson, D. W., Ketterer, M. E., Hymus, G. J., et al. (2004). $\mathrm{CO}_{2}$ elicits long-term decline in nitrogen fixation. Science 304, 1291-1291. doi: 10.1126/science.1095549

Hungria, M., and Franco, A. A. (1993). Effects of high temperature on nodulation and nitrogen fixation by Phaseolus vulgaris L. Plant Soil 149, 95-102. doi: 10.1007/bf00010766

Hungria, M., and Vargas, M. A. T. (2000). Environmental factors affecting $\mathrm{N}_{2}$ fixation in grain legumes in the tropics, with an emphasis on Brazil. Field Crops Res. 65, 151-164. doi: 10.1016/s0378-4290(99)00084-2

Johnson, S. N., Benefer, C. M., Frew, A., Griffiths, B. S., Hartley, S. E., Karley, A. J., et al. (2016a). New frontiers in belowground ecology for plant protection from root-feeding insects. Appl. Soil Ecol. 108, 96-107. doi: 10.1016/j.apsoil.2016. 07.017

Johnson, S. N., Gherlenda, A. N., Frew, A., and Ryalls, J. M. W. (2016b). The importance of testing multiple environmental factors in legume-insect research: replication, reviewers and rebuttal. Front. Plant Sci. 7:489. doi: 10.3389/fpls. 2016.00489 
Johnson, S. N., Hartley, S. E., Ryalls, J. M. W., Frew, A., DeGabriel, J. L., Duncan, M., et al. (2017). Silicon-induced root nodulation and synthesis of essential amino acids in a legume is associated with higher herbivore abundance. Funct. Ecol. 31, 1903-1909. doi: 10.1111/1365-2435. 12893

Johnson, S. N., and Jones, T. H. (2017). "Emerging issues and future perspectives for global climate change studies," in Global Climate Change and Terrestrial Invertebrates, eds S. N. Johnson and T. H. Jones (Chichester: John Wiley \& Sons, Ltd), 368-377. doi: 10.1002/9781119070894

Johnson, S. N., and McNicol, J. W. (2010). Elevated $\mathrm{CO}_{2}$ and abovegroundbelowground herbivory by the clover root weevil. Oecologia 162, 209-216. doi: 10.1007/s00442-009-1428-4

Katayama, N., Nishida, T., Zhang, Z. Q., and Ohgushi, T. (2010). Belowground microbial symbiont enhances plant susceptibility to a spider mite through change in soybean leaf quality. Popul. Ecol. 52, 499-506. doi: 10.1007/s10144010-0207-8

Kempel, A., Brandl, R., and Schädler, M. (2009). Symbiotic soil microorganisms as players in aboveground plant-herbivore interactions - the role of rhizobia. Oikos 118, 634-640. doi: 10.1111/j.1600-0706.2009.17418.x

Lam, S. K., Chen, D. L., Norton, R., Armstrong, R., and Mosier, A. R. (2012). Nitrogen dynamics in grain crop and legume pasture systems under elevated atmospheric carbon dioxide concentration: a metaanalysis. Glob. Change Biol. 18, 2853-2859. doi: 10.1111/j.1365-2486.2012. 02758.x

Lamb, R. J., and MacKay, P. A. (1988). Effects of temperature on developmental rate and adult weight of Australian populations of Acyrthosiphon pisum (Harris) (Homoptera: Aphididae). Mem. Entomol. Soc. Can. 120, 49-55. doi: 10.4039/ entm120146049-1

Lindroth, R. L., and Raffa, K. F. (2016). "Experimental approaches for assessing invertebrate responses to global change factors," in Global Climate Change and Terrestrial Invertebrates, eds S. N. Johnson and T. H. Jones (Chichester: John Wiley \& Sons), 30-45. doi: 10.1002/9781119070894.ch3

Mackay, P. A., Lamb, R. J., and Smith, M. A. H. (1993). Variability in life-history traits of the aphid, Acyrthosiphon pisum (Harris), from sexual and asexual populations. Oecologia 94, 330-338. doi: 10.1007/Bf00317106

Mali, M., and Aery, N. C. (2008). Silicon effects on nodule growth, dry-matter production, and mineral nutrition of cowpea (Vigna unguiculata). J. Plant Nutr. Soil Sci. 171, 835-840. doi: 10.1002/jpln.200700362

Mattson, W. J. (1980). Herbivory in relation to plant nitrogen content. Annu. Rev. Ecol. Syst. 11, 119-161. doi: 10.1146/annurev.es.11.110180.001003

McLarnon, E., McQueen-Mason, S., Lenk, I., and Hartley, S. E. (2017). Evidence for active uptake and deposition of Si-based defenses in tall fescue. Front. Plant Sci. 8:1199. doi: $10.3389 /$ fpls.2017.01199

Miyake, Y., and Takahashi, E. (1985). Effect of silicon on the growth of soybean plants in a solution culture. Soil Sci. Plant Nutr. 31, 625-636. doi: 10.1080/ 00380768.1985.10557470

Montllor, C. B., Maxmen, A., and Purcell, A. H. (2002). Facultative bacterial endosymbionts benefit pea aphids Acyrthosiphon pisum under heat stress. Ecol. Entomol. 27, 189-195. doi: 10.1046/j.1365-2311.2002.00393.x

Nelwamondo, A., and Dakora, F. D. (1999). Silicon promotes nodule formation and nodule function in symbiotic cowpea (Vigna unguiculata). New Phytol. 142, 463-467. doi: 10.1046/j.1469-8137.1999.00409.x

Newman, J. A., Anand, M., Henry, H. A. L., Hunt, S., and Gedalof, Z. (2011). Climate Change Biology. Wallingford, UK: CABI. doi: 10.1079/9781845937485. 0000

Norby, R. J. (1987). Nodulation and nitrogenase activity in nitrogen-fixing woody plants stimulated by $\mathrm{CO}_{2}$ enrichment of the atmosphere. Physiol. Plantarum 71 , 77-82. doi: 10.1111/j.1399-3054.1987.tb04620.x

Piha, M. I., and Munns, D. N. (1987). Sensitivity of the common bean (Phaseolus vulgaris L) symbiosis to high soil temperature. Plant Soil 98, 183-194. doi: $10.1007 /$ bf 02374822

Pineda, A., Zheng, S.-J., van Loon, J. J. A., Pieterse, C. M. J., and Dicke, M. (2010). Helping plants to deal with insects: the role of beneficial soil-borne microbes. Trends Plant Sci. 15, 507-514. doi: 10.1016/j.tplants.2010.05.007

Quinn, M. A., and Hower, A. A. (1986). Effects of root nodules and taproots on survival and abundance of Sitona hispidulus (Coleoptera, Curculionidae) on Medicago sativa. Ecol. Entomol. 11, 391-400. doi: 10.1111/j.1365-2311.1986. tb00318.x
Reidinger, S., Ramsey, M. H., and Hartley, S. E. (2012). Rapid and accurate analyses of silicon and phosphorus in plants using a portable X-ray fluorescence spectrometer. New Phytol. 195, 699-706. doi: 10.1111/j.1469-8137.2012.04179.x

Reynolds, O. L., Keeping, M. G., and Meyer, J. H. (2009). Silicon-augmented resistance of plants to herbivorous insects: a review. Ann. Appl. Biol. 155, 171-186. doi: 10.1111/j.1744-7348.2009.00348.x

Robinson, E. A., Ryan, G. D., and Newman, J. A. (2012). A meta-analytical review of the effects of elevated $\mathrm{CO}_{2}$ on plant-arthropod interactions highlights the importance of interacting environmental and biological variables. New Phytol. 194, 321-336. doi: 10.1111/j.1469-8137.2012.04074.x

Rogers, A., Ainsworth, E. A., and Leakey, A. D. B. (2009). Will elevated carbon dioxide concentration amplify the benefits of nitrogen fixation in legumes? Plant Physiol. 151, 1009-1016. doi: 10.1104/pp.109.144113

Russell, J. A., and Moran, N. A. (2005). Horizontal transfer of bacterial symbionts: heritability and fitness effects in a novel aphid host. Appl. Environ. Microbiol. 71, 7987-7994. doi: 10.1128/AEM.71.12.7987-7994.2005

Ryalls, J. M. W. (2016). The Impacts of Climate Change and Belowground Herbivory on Aphids via Primary Metabolites. Ph.D. Thesis, Western Sydney University, Sydney,NSW.

Ryalls, J. M. W., and Harrington, R. (2017). "Climate and atmospheric change impacts on aphids as vectors of plant diseases," in Global Climate Change and Terrestrial Invertebrates, eds S. N. Johnson and T. H. Jones (Chichester: John Wiley \& Son), $148-175$

Ryalls, J. M. W., Riegler, M., Moore, B. D., and Johnson, S. N. (2013a). Biology and trophic interactions of lucerne aphids. Agric. For. Entomol. 15, 335-350. doi: $10.1111 /$ afe. 12024

Ryalls, J. M. W., Riegler, M., Moore, B. D., Lopaticki, G., and Johnson, S. N. (2013b). Effects of elevated temperature and $\mathrm{CO}_{2}$ on abovegroundbelowground systems: a case study with plants, their mutualistic bacteria and root/shoot herbivores. Front. Plant Sci. 4:445. doi: 10.3389/fpls.2013.00445

Ryle, G. J. A., and Powell, C. E. (1992). The influence of elevated $\mathrm{CO}_{2}$ and temperature on biomass production of continuously defoliated white clover. Plant Cell Environ. 15, 593-599. doi: 10.1111/j.1365-3040.1992.tb01493.x

Schortemeyer, M., Hartwig, U. A., Hendrey, G. R., and Sadowsky, M. J. (1996). Microbial community changes in the rhizospheres of white clover and perennial ryegrass exposed to Free Air Carbon dioxide Enrichment (FACE). Soil Biol. Biochem. 28, 1717-1724. doi: 10.1016/S0038-0717(96)00243-X

Soussana, J. F., and Hartwig, U. A. (1996). The effects of elevated $\mathrm{CO}_{2}$ on symbiotic $\mathrm{N}_{2}$ fixation: a link between the carbon and nitrogen cycles in grassland ecosystems. Plant Soil 187, 321-332. doi: 10.1007/BF00017097

Sun, Y., Guo, H., and Ge, F. (2016). Plant-aphid interactions under elevated $\mathrm{CO}_{2}$ : some cues from aphid feeding behavior. Front. Plant Sci. 7:502. doi: 10.3389/ fpls.2016.00502

Whitaker, M. R. L., Katayama, N., and Ohgushi, T. (2014). Plant-rhizobia interactions alter aphid honeydew composition. Arthropod Plant Interact. 8, 213-220. doi: 10.1007/s11829-014-9304-5

Whittington, H. R., Tilman, D., and Powers, J. S. (2013). Consequences of elevated temperatures on legume biomass and nitrogen cycling in a field warming and biodiversity experiment in a North American prairie. Funct. Plant Biol. 40, 1147-1158. doi: 10.1071/FP12345

Zahran, H. H. (1999). Rhizobium-legume symbiosis and nitrogen fixation under severe conditions and in an arid climate. Microbiol. Mol. Biol. Rev. 63, 968-989.

Zanetti, S., Hartwig, U. A., Luscher, A., Hebeisen, T., Frehner, M., Fischer, B. U., et al. (1996). Stimulation of symbiotic $\mathrm{N}_{2}$ fixation in Trifolium repens $\mathrm{L}$. under elevated atmospheric $\mathrm{pCO}_{2}$ in a grassland ecosystem. Plant Physiol. 112, 575-583. doi: 10.1104/pp.112.2.575

Conflict of Interest Statement: The authors declare that the research was conducted in the absence of any commercial or financial relationships that could be construed as a potential conflict of interest.

Copyright $\odot 2018$ Johnson, Ryalls, Gherlenda, Frew and Hartley. This is an openaccess article distributed under the terms of the Creative Commons Attribution License (CC BY). The use, distribution or reproduction in other forums is permitted, provided the original author(s) and the copyright owner are credited and that the original publication in this journal is cited, in accordance with accepted academic practice. No use, distribution or reproduction is permitted which does not comply with these terms. 